\title{
Methylfolate as Monotherapy in Depression. A Pilot Randomised Controlled Trial
}

\begin{abstract}
Keywords: Methylfolate, Depression, Monotherapy, Methylation, Amitriptyline

Abstract

Background: The commonest neuropsychiatric complication of severe folate deficiency is depression. Placebo controlled trials of folates as adjunctive therapy in major depression have confirmed that they enhance the response to standard antidepressant medication, even in the absence of folate deficiency. We have undertaken a pilot randomised controlled trial of 5-methyltetrahydrofolate (5MTHF) monotherapy against Amitriptyline in out-patients with mild to moderate depression.
\end{abstract}

Methods: 31 patients, a ged 20 - 69 years with DSM-111-R criteria for a depressive episode of mild to moderate severity and a Montgomery Asberg Depression Score (MADS) of at least 14 were randomly allocated to 5-MTHF 50 mgs ( 25 mgs biologically active) or Amitriptyline 150 mgs for 6 weeks. Clinical response was defined as a fall in MADS of $25 \%$ or more. Non-responders to initial therapy were crossed over to the alternative active therapy for a further six weeks. Haemoglobin, mean cell volume, serum and red cell folate and serum vitamin B12 were measured at entry to the study, after six weeks of initial and crossover treatment and at six months.

Results: Of 19 patients randomised $(n=16)$ or crossed over $(n=3)$ to treatment with $5-\mathrm{MTHF}$ for six weeks, eight $(42 \%)$ responded. Of 20 patients randomised $(n=15)$ or crossed over $(n=5)$ to Amitriptyline, seven (35\%) responded. Only 3 patients (10\%) had low or borderline red cell folate values at randomisation. Response to 5-MTHF was associated with a significantly greater rise in red cell folate.

Conclusions: Placebo controlled trials of 5-MTHF as monotherapy in depression would be justifiable. Our observations together with studies of S-adenosylmethionine (SAM) and nitrous oxide $\left(\mathrm{N}_{2} \mathrm{O}\right)$ are consistent with the hypothesis that 5-MTHF has intrinsic mood elevating properties in some patients.

\section{Introduction}

Research by ourselves and others in haematological, neurological, psychiatric and geriatric settings indicate an aetiological link between folate deficiency, depression and cognitive decline [1-5]. In 1990 we reported that in a double blind placebo controlled trial in adult patients with major depression associated with folate deficiency the addition of $15 \mathrm{mgs}$ of 5-methyltetrahydrofolate (5-MTHF) daily to standard antidepressant medication significantly enhanced recovery over 6 months [6]. The next logical step was to evaluate whether 5 -MTHF had mood elevating properties in depressed patients in the absence of folate deficiency? We therefore undertook a pilot randomised controlled trial comparing 5-MTHF as monotherapy with a standard antidepressant for 6 weeks in adult outpatients with mild to moderate depression. Between 2000 and 2005 we submitted the outcome of this trial to 5 journals, all of whom rejected the report, mainly due to scepticism that 5-MTHF could have intrinsic mood elevating properties in the absence of folate deficiency.

Recently an American group has confirmed that 5-MTHF is a

\section{Journal of \\ Neurology and Psychology}

\section{Edward H Reynolds ${ }^{2 *}$, Richard Crellin ${ }^{1}$, Teodoro Bottiglieri ${ }^{4,5}$, Malcolm Laundy ${ }^{4}$, Brian K Toone ${ }^{1}$ and Michael WP Carney ${ }^{3}$}

${ }^{1}$ Department of Psychological Medicine, King's College Hospital, University of London, London SE5 8AF, UK

${ }^{2}$ Department of Clinical Neurosciences, King's College Hospital, University of London, London SE5 8AF, UK

${ }^{3}$ Department of Psychological Medicine, Northwick Park Hospital, Harrow, Middlesex HA1 3UJ, UK

${ }^{4}$ Department of Haematology, Northwick Park Hospital, Harrow, Middlesex HA1 3UJ, UK

${ }^{5}$ Institute of Metabolic Disease, Baylor Research Institute, Dallas, Texas, USA

\section{*Address for Correspondence}

Edward $\mathrm{H}$ Reynolds MD, FRCP, FRCPsych, Department of Clinical Neurosciences, King's College Hospital, University of London, London SE5 8AF, UK, E-mail: reynolds@buckles.u-net.com

Copyright: (c) 2015 Reynolds EH, et al. This is an open access article distributed under the Creative Commons Attribution License, which permits unrestricted use, distribution, and reproduction in any medium, provided the original work is properly cited.

Submission: 11 March 2015

Accepted: 19 May 2015

Published: 23 May 2015

Reviewed \& Approved by: Dr. Xin-Fu Zhou, Professor, School of Pharmacy and Medical Sciences, University of South Australia, Australia

useful adjunctive therapy for SSRI-resistant major depression in a randomised double blind parallel-sequential trial [7]. In contrast to our own adjunctive trial [6] none of their patients were folate deficient. We therefore consider the time and intellectual climate is now appropriate to re-submit our pilot 5-MTHF monotherapy trial for publication. We are further encouraged to do so by increasing concern that all trial data should be published [8]. Much of this concern is directed at the failure to publish negative trial data, but in this instance we consider that interesting positive trial data, albeit pilot, warrants publication.

\section{Patients and Methods}

Thirty six out-patients referred to the Departments of Psychological Medicine at King's College and Northwick Park Hospitals with a DSM-111-R Depressive Episode of mild to moderate severity and a Montgomery Asberg Depressive Score (MADS) [9] of at least 14 were entered into a pilot randomised controlled trial of $50 \mathrm{mgs} 5$-MTHF (consisting of a racemic mixture of $25 \mathrm{mgs}$ of active L-isomer and $25 \mathrm{mgs}$ of inactive D-isomer) against $150 \mathrm{mgs}$ Amitriptyline. Exclusion criteria included clinical evidence of cognitive impairment; other psychiatric disorders; serious physical illness; alcohol/drug abuse; and pregnancy.

Patients were referred for assessment and treatment in these two hospital out-patient settings, i.e. secondary care, by their general practitioners because of failure to respond to treatment in primary care. Those patients still on psychotropic medication underwent a two-week wash-out period. All patients had an initial run-in period of two weeks on placebo in an attempt to exclude placebo-responders from the active phase of the trial. Five patients were excluded. Thirty one placebo non-responders were then randomised blindly either to 5-MTHF (50 mgs) or Amitriptyline (rising to $150 \mathrm{mgs}$ daily over 
Citation: Reynolds EH, Crellin R, Bottiglieri T, Laundy M, Toone BK, et al. Methylfolate as Monotherapy in Depression. A Pilot Randomised Controlled Trial. J Neurol Psychol. 2015;3(1): 5

one week) for six weeks. Non-responders to initial active treatment were then crossed over to alternative active treatment for a further six weeks. Patients failing to respond to both treatments were withdrawn. Patients responding to initial or cross-over treatment were followed for up to six months without any change of therapy (Figure 1).

The definition of response was a fall in MADS of twenty five percent or more. Scores were measured at minus 2 weeks, $0,2,4$ and 6 weeks of initial or cross-over treatment, and at six months. The MADS ratings were undertaken by one and the same doctor.

Haemoglobin, mean cell volume, serum and red cell folate and serum vitamin B12 were measured at entry to the active phase of treatment, after 6 weeks of initial and cross-over treatment, and at
6 months. Haematological and vitamin data were unknown to the clinical investigators until trial completion. Serum and red cell folate were measured by microbiological assay using Lactobacillus casei [10]. Serum vitamin B12 was determined by a radio isotope dilution method [11].

A two-tailed Mann-Whitney non-parametric $t$-test was used to determine significant differences between groups; the Pearson correlation co-efficient to determine the relationship between red cell folate and MADS.

The trial was approved by the Ethics Committees of King's College and Northwick Park Hospitals. All patients gave informed consent.

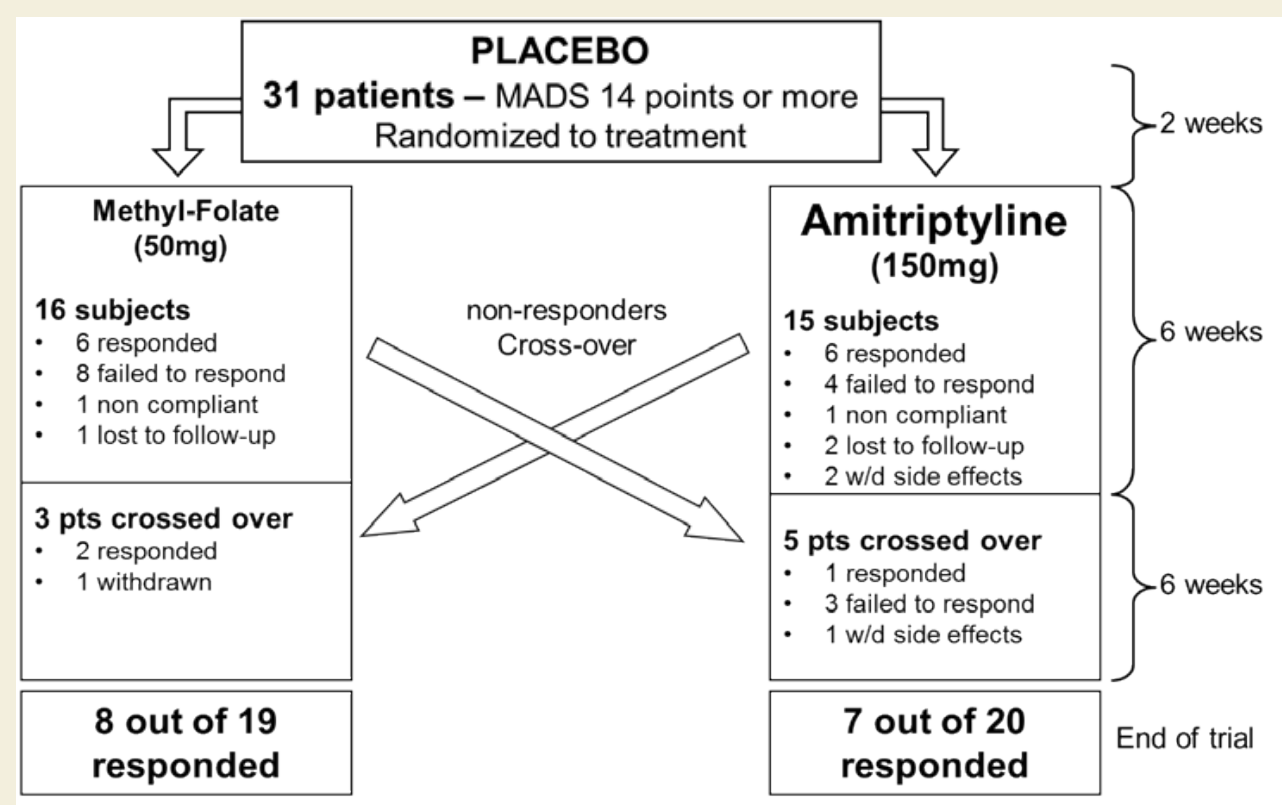

Figure 1: Trial flow chart.

Table 1: Patient demographic and haematological characteristics by initial randomisation.

\begin{tabular}{|c|c|c|c|}
\hline & $\begin{array}{l}\text { Randomisation to 5-MTHF } \\
\qquad(n=16)\end{array}$ & $\begin{array}{l}\text { Randomisation to Amitriptyline } \\
\qquad(\mathrm{n}=15)\end{array}$ & $\begin{array}{l}\text { Total population } \\
\qquad(n=31)\end{array}$ \\
\hline \multirow[t]{2}{*}{ Age (years) } & 49 & 41 & 45 \\
\hline & $(31-67)$ & $(20-69)$ & $(20-69)$ \\
\hline \multirow[t]{2}{*}{ Sex } & $M=4$ & $M=4$ & $M=8$ \\
\hline & $\mathrm{F}=12$ & $\mathrm{~F}=11$ & $F=23$ \\
\hline \multirow[t]{2}{*}{ MADS score } & 22 & 22 & 22 \\
\hline & $(15-31)$ & $(15-26)$ & $(15-31)$ \\
\hline \multirow[t]{2}{*}{ Haemoglobin (mg/l) } & 13.3 & 13.6 & 13.4 \\
\hline & $(11.4-15.9)$ & $(12.0-15.4)$ & $(11.4-15.9)$ \\
\hline \multirow[t]{2}{*}{ MCV (fl) } & 89.7 & 90.5 & 90.1 \\
\hline & $(81.7-100.1)$ & $(83.5-100.0)$ & $(81.7-100.1)$ \\
\hline \multirow[t]{2}{*}{ Red cell folate $(\mathrm{ng} / \mathrm{ml})$} & 344 & 295 & 319 \\
\hline & $(151-676)$ & $(157-564)$ & $(151-676)$ \\
\hline Serum folate $(\mathrm{ng} / \mathrm{ml})$ & 8.3 & 5.5 & 6.6 \\
\hline \multirow[t]{2}{*}{ Serum B12 (pg/ml) } & 362 & 301 & 346 \\
\hline & $(150-658)$ & $(100-780)$ & $(100-780)$ \\
\hline
\end{tabular}

There were no significant differences between the two randomised groups. 
Citation: Reynolds EH, Crellin R, Bottiglieri T, Laundy M, Toone BK, et al. Methylfolate as Monotherapy in Depression. A Pilot Randomised Controlled Trial. J Neurol Psychol. 2015;3(1): 5

ISSN: 2332-3469

\section{Results}

Table 1 summarises the demographic and haematological characteristics of 16 patients randomised to 5-MTHF and 15 patients randomised to Amitriptyline. Three patients (10\%) had low or borderline red cell folate values $(<200 \mathrm{ng} / \mathrm{ml})$.

Of 16 patients randomised to 5-MTHF, 6 responded to treatment by six weeks (mean reduction in MADS $45 \%$, range -33.3 to $-53.3 \%$. Eight patients did not respond (MADS $+20 \%$, range +62.5 to $-12.5 \%$ ). One patient did not comply with the protocol. One patient was lost to follow-up.

Of 15 patients randomised to Amitriptyline, 6 responded to treatment (mean reduction in MADS 59\%, range -30 to - 91\%). Four patients did not respond (MADS $-4 \%$, range +20 to $-24 \%$ ). Two patients withdrew with unacceptable side-effects. One patient did not comply with the protocol. Two were lost to follow-up.

Three patients were crossed from Amitriptyline to 5-MTHF. Two patients responded at 6 weeks with a mean fall in MADS of 52\%, (range -46 to $-58 \%$ ). One patient deteriorated and was withdrawn. Five patients were crossed from 5-MTHF to Amitriptyline. Only 1 responded at 6 weeks (MADS reduction 71\%). Three did not respond (MADS $+3 \%$, range +40 to $-19 \%$ ). One patient withdrew with unacceptable side-effects. Four patients declined cross-over.

Of 19 patients randomised $(\mathrm{n}=16)$ or crossed over $(\mathrm{n}=3)$ to treatment with 5-MTHF, 8 (42\%) responded. Of 20 patients randomised $(\mathrm{n}=15)$ or crossed over $(\mathrm{n}=5)$ to Amitriptyline, $7(35 \%)$ responded to treatment (Figure 1).

Of eight patients responding to 5-MTHF, 6 maintained their improvement at 6 months. Two were lost to follow-up. Of 7 patients responding to Amitriptyline, 5 remained well at 6 months. 1 withdrew due to pregnancy. 1 was lost to follow-up.

Complete pre and post ( 6 weeks) biochemical data was available in 7 5-MTHF responders and 6 non-responders (Table 2); and in 6 Amitriptyline responders and 6 non-responders. No changes in biochemical parameters occurred in Amitriptyline responders or non-responders. In folate responders red cell folate rose considerably from a baseline mean of $330 \mathrm{ng} / \mathrm{ml}$ to $907 \mathrm{ng} / \mathrm{ml}$. In folate non- responders there was a more modest rise from a baseline mean of 311 $\mathrm{ng} / \mathrm{ml}$ to $496 \mathrm{ng} / \mathrm{ml}, \mathrm{p}=0.0044, \mathrm{t}=3.574, \mathrm{df}=11$. Furthermore, for the combined 13 folate treated patients there was a significant correlation between the percentage change in red cell folate and the percentage change in MADS $(\mathrm{r}=0.65, \mathrm{p}<0.016)$ (Figure 2). The improvement in MADS was significantly greater in 6 patients with red cell folate $>1000 \mathrm{ng} / \mathrm{ml}$ compared to 7 patients with folate levels $<1000 \mathrm{ng} / \mathrm{ml}$ $(\mathrm{p}=0.022)($ Table 2$)$.

\section{Discussion}

Depressed patients with uncorrected folate deficiency respond less well to antidepressant therapy $[12,13]$. Double blind placebo controlled trials have shown that folic acid or 5-MTHF enhance the response to psychotropic medication in patients with mood disorders with or without folate deficiency $[6,7,14,15]$. An open trial of 5-MTHF in elderly depressed patients [16] and a pilot double blind study of 5-MTHF monotherapy in geriatric patients with dementia [17] suggest a positive effect on mood in the absence of folate deficiency.

Our trial was designed to explore the possibility that the vitamin has intrinsic antidepressant properties, irrespective of folate status. 5-MTHF was chosen because it is the active transport form of the vitamin into the nervous system $[18,19]$. As the first randomised study of the vitamin as monotherapy, ethical considerations dictated only patients with a DSM-111-R Depressive Episode of mild to moderate severity were included. As an exploratory pilot trial it did not have the power to detect important differences in the efficacy of the two medications. Overall 8 of 19 (42\%) patients treated with 5-MTHF and 7 of $20(35 \%)$ patients treated with Amitriptyline responded. No side effects were reported with 5-MTHF, whereas 3 patients were withdrawn from the study due to unacceptable side effects with Amitriptyline.

The most interesting outcome was the relationship between antidepressant response to 5-MTHF and the rise in red cell folate levels. Table 2 shows that all the patients responding to 5-MTHF exhibited a considerable rise in red cell folate at 6 weeks. The only patient in whom red cell folate was less than $1000 \mathrm{ng} / \mathrm{ml}$ (the upper limit of the sensitivity of the assay) was a folate deficient subject. Patients not responding to 5-MTHF showed a more modest rise in red cell folate. Only 1 patient in each group returned unused medication. Whatever

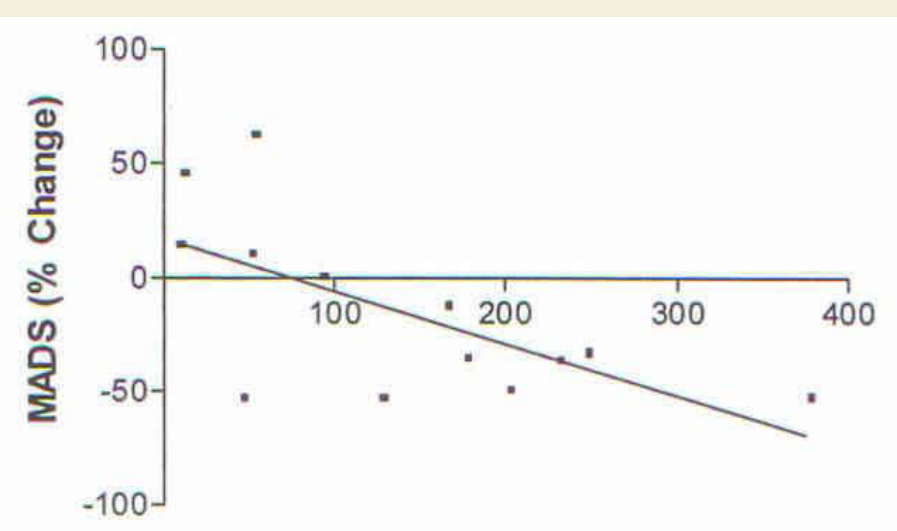

RBC folate ( $\%$ change)

Figure 2: Relationship of change in red cell folate to change in MADS at six weeks in depressed patients treated with 5-MTHF. 
Citation: Reynolds EH, Crellin R, Bottiglieri T, Laundy M, Toone BK, et al. Methylfolate as Monotherapy in Depression. A Pilot Randomised Controlled Trial. J Neurol Psychol. 2015;3(1): 5

the mechanism it suggests that response to vitamin treatment may be influenced in part by the amount of 5-MTHF entering the nervous system.

We used a large dose of 5-MTHF containing $25 \mathrm{mgs}$ of active 5-MTHF. Papakostas et al. found that $15 \mathrm{mgs}$ but not $7.5 \mathrm{mgs}$ of the $100 \%$ biologically active L-5-MTHF was significantly useful as adjunctive therapy [7]. In their adjunctive studies Coppen et al. [14] and Coppen and Bailey [15] used small doses of folic acid which is converted to 5-MTHF in the blood. Venkatasubramanian et al. reported that $5 \mathrm{mgs}$ of folic acid was more beneficial than $1.5 \mathrm{mgs}$ as an adjunctive to fluoxetine at 6 weeks [20]. We recommend that future studies should continue to utilise 5-MTHF with monitoring of red cell folate. Plasma homocysteine, which is raised in some patients with major depression [21], and folate genetic polymorphisms [22] could also be incorporated utilising statistical methods aimed at identifying subgroups of responders and non-responders [23].

As this was an exploratory trial of a novel treatment the sample sizes were relatively small and did not have the power to detect significant differences in efficacy. We were concerned to address the issue of placebo responses as far as practical and ethical. Ethical considerations dictated that we could not include a placebo arm in our initial exploration of a new treatment [24]. However our patients were all treated in a secondary care setting, having been referred by their general practitioners because of failure to respond to treatment in primary care. Thus in general they did not conform to the placebo pattern response (PPR) referred to by Sonawalla and Rosenbaum [24]. Furthermore we also addressed the issue by including a placebo run-in period as a result of which 5 patients were excluded from the active trial.
Another concern is that with only modest numbers of responses to either 5-MTHF (42\%) and Amitriptyline (35\%) neither medication is an antidepressant. While this may be plausible for 5-MTHF it seems unlikely for the well established Amitriptyline. In the 1990's there seems to have been an exaggerated view of the response rate to antidepressant drugs, which has been modified and reduced by recent meta-analyses showing more modest figures such as our own $[25,26]$.

A further possible limitation is that the cut-off point for response on the MADS was too low at $25 \%$. The latter was dictated by the fact that we were only treating subjects with mild to moderate depression. However, the actual response scores for Amitriptyline were 30\% to $91 \%$ (mean 59\%) and for 5-MTHF $34 \%$ to $53 \%$ (mean $45 \%$ ), and in all cases responses were clinically readily apparent.

In this pilot study we have not shown that 5-MTHF monotherapy has antidepressant properties in subjects who are not folate deficient. Confirmation of our hypothesis will require a large-scale placebo controlled trial. We do claim however that there is sufficient encouragement from this exploratory trial to justify such a placebo controlled trial.

There is a natural reluctance to conceive of a simple vitamin having mood elevating properties in the absence of deficiency of the vitamin. But other clinical and experimental observations support our hypothesis. The euphoriant effects of nitrous oxide $\left(\mathrm{N}_{2} \mathrm{O}\right.$, laughing gas) are well known. It is probable that the demonstrated rapid rise in brain levels of 5-MTHF as a result of an acute block in 5-MTHF metabolism underlies these effects [27]. S-adenosylmethionine (SAM) denotes its methyl group, ultimately derived from 5-MTHF, in innumerable genomic and non-genomic methylation reactions in the nervous system $[27,28]$. Many studies have confirmed that SAM has

Table 2: Baseline and six weeks red cell folate and MADS scores in 5-MTHF responders and non-responders.

\begin{tabular}{|c|c|c|c|c|c|c|c|c|}
\hline & \multicolumn{4}{|c|}{ RBC Folate $(\mathrm{ng} / \mathrm{ml})$} & \multicolumn{4}{|c|}{ MADS } \\
\hline & Baseline & 6 weeks & difference & $\%$ change & Baseline & 6 weeks & difference & \% change \\
\hline \multicolumn{9}{|c|}{ Responders } \\
\hline & 358 & $>1000$ & 642 & 179.3 & 31 & 20 & -11 & -35.5 \\
\hline & 151 & 347 & 196 & 129.8 & 15 & 7 & -8 & -53.3 \\
\hline & 676 & $>1000$ & 324 & 47.9 & 15 & 7 & -8 & -53.3 \\
\hline & 300 & $>1000$ & 700 & 233.3 & 19 & 12 & -7 & -36.8 \\
\hline & 286 & $>1000$ & 714 & 249.7 & 21 & 14 & -7 & -33.3 \\
\hline & 209 & $>1000$ & 791 & 378.5 & 17 & 8 & -9 & -52.9 \\
\hline & 329 & $>1000$ & 671 & 204.0 & 24 & 12 & -12 & -50.0 \\
\hline Mean & 330 & 907 & 577 & 203 & 20 & 11 & & \\
\hline$+\mid-S D$ & 168 & 247 & 224 & 103 & 6 & 5 & & \\
\hline $\mathbf{N}$ & 7 & 7 & 7 & 7 & 7 & 7 & & \\
\hline \multicolumn{9}{|c|}{ Non-responders } \\
\hline & 474 & 923 & 449 & 94.7 & 14 & 14 & 0 & 0.0 \\
\hline & 413 & 457 & 44 & 10.7 & 21 & 24 & 3 & 14.3 \\
\hline & 168 & 450 & 282 & 167.9 & 16 & 14 & -2 & -12.5 \\
\hline & 244 & 276 & 32 & 13.1 & 31 & 45 & 14 & 45.2 \\
\hline & 237 & 366 & 129 & 54.4 & 16 & 26 & 10 & 62.5 \\
\hline Mean & 311 & 496 & 185 & 66 & 20 & 24 & & \\
\hline$+\mid-S D$ & 116 & 224 & 159 & 59 & 6 & 11 & & \\
\hline $\mathbf{N}$ & 6 & 6 & 6 & 6 & 6 & 6 & & \\
\hline
\end{tabular}

Difference in red cell folate, responders $v$ non responders, $t=3.574, \mathrm{df}=11, \mathrm{p}<0.0044$ 
Citation: Reynolds EH, Crellin R, Bottiglieri T, Laundy M, Toone BK, et al. Methylfolate as Monotherapy in Depression. A Pilot Randomised Controlled Trial. J Neurol Psychol. 2015;3(1): 5.

antidepressant properties in the absence of folate deficiency $[28,29]$. Our studies of the association of folate deficiency with depression and Italian observations of the antidepressant effect of SAM led us to conclude that methylation processes in the brain are a key to understanding the biology of mood [30]. This includes the influence of methylation on monoamine metabolism [21].

Mood is not the only mental function associated with folate, SAM and methylation. We have emphasised the influence of the vitamin on other aspects of cognitive function [2]. Recently placebo controlled trials suggest that folic acid may enhance those domains of cognitive function associated with ageing $[2,31]$ and, in combination with vitamin $\mathrm{B} 12$ and vitamin B6, may play a role in preventing cerebral atrophy [32]. There is a need for greater investment in this promising and less toxic approach to mental illness, including a placebo controlled trial of 5-MTHF as monotherapy in depressed patients with and without folate deficiency.

\section{References}

1. Reynolds EH (1968) Mental effects of anti-convulsants, and folic acid metabolism. Brain 91: 197-214.

2. Reynolds EH (2014) The neurology of folic acid deficiency. In: Biller J and Ferro JM (Eds). Handbook of Clinical Neurology, Neurologic Aspects of Systemic Disease Part 11. Amsterdam: Elsevier BV, 120: 927-943.

3. Botez MI, Reynolds EH (Eds) (1979) Folic Acid in Neurology, Psychiatry and Internal Medicine. New York: Raven Press.

4. Shorvon SD, Carney MW, Chanarin I, Reynolds EH (1980) The neuropsychiatry of megaloblastic anaemia. BMJ 281: 1036-1042.

5. Bottiglieri T, Crellin R, Reynolds EH (1995) Folate and neuropsychiatry. In: Bailey LB (Ed). Folate in health and disease. New York: Marcel Dekker: pp 435-462.

6. Godfrey PS, Toone BK, Carney MW, Flynn TG, Bottiglieri T, et al. (1990) Enhancement of recovery from psychiatric illness by methylfolate. Lancet 336: 392-395.

7. Papakostas GI, Shelton RC, Zajecka JM, Etemad B, Rickels K, et al. (2012) L-Methylfolate as adjunctive therapy for SSRI-resistant major depression: results of two randomised, double-blind, parallel-sequential trials. Am J Psychiatry 169: 1267-1274.

8. Chalmers I, Glasziou P, Godlee F (2013) All trials must be registered and the results published. BMJ 346: f105.

9. Montgomery SA, Asberg M (1979) A new depression scale designed to be sensitive to change. Br J Psychiatry 134: 382-389.

10. Chanarin I (1989) Laboratory haematology: an account of laboratory techniques. New York: Churchill Livingstone.

11. Muir M, Chanarin I (1983) Solid phase vitamin B12 assays using polyacrylamide-bound intrinsic factor and polyacrylamide-bound R-binder. $\mathrm{Br}$ J Haematol 53: 423-435.

12. Reynolds EH, Preece JM, Bailey J, Coppen A (1970) Folate deficiency in depressive illness. Br J Psychiatry 117: 287-292.

13. Papakostas GI, Petersen T, Lebowitz BD, Mischoulon D, Ryan JL, et al. (2005) The relationship between serum folate, vitamin B12, and homocysteine levels in major depressive disorder and the timing of improvement with fluoxetine. Int J Neuropsychopharmacol 8: 523-528.

14. Coppen A, Chaudry S, Swade C (1986) Folic acid enhances lithium prophylaxis. J Affect Disord 10: 9-13.

15. Coppen A, Bailey J (2000) Enhancement of the antidepressant action of fluoxetine by folic acid: a randomised, placebo controlled trial. J Affect Disord 60: $121-130$

16. Guaraldi GP, Fava M, Mazzi F, La Greca P (1993) An open trial of methyltetrahydrofolate in elderly depressed patients. Ann Clin Psychiatry 5: 101-105.

17. Passari M, Cuciniotta D, Abate G, Senin U, Ventura A, et al. (1993) Oral 5'-methyltetrahydrofolic acid in senile organic mental disorders with depression: results of a double-blind multicentre study. Aging (Milano) 5: 6371

18. Reynolds EH, Gallagher BB, Mattson RH, Bowers M, Johnson AL (1972) Relationship between serum and cerebrospinal fluid folate. Nature 240: 155157.

19. Spector R (1979) Cerebrospinal fluid folate and the blood-brain barrier. In Botez MI, Reynolds EH (Eds). Folic acid in neurology, psychiatry and internal medicine. New York: Raven Press, pp 87-94.

20. Venkatasubramanian R, Kumar CN, Pandey RS (2013) A randomised double-blind comparison of fluoxetine augmentation by high and low dosage folic acid in patients with depressive episodes. J Affect Disord 150: 644-648.

21. Bottiglieri T, Laundy M, Crellin R, Toone BK, Carney MW, et al. (2000) Homocysteine, folate, methylation and monoamine metabolism in depression. J Neurol Neurosurg Psychiatry 69: 228-232.

22. Jamerson $B D$, Payne ME, Garrett ME, Ashley-Koch AE, Speer MC et al. (2013) Folate metabolism genes, dietary folate and response to antidepressant medications in late life depression. Int J Geriatr Psychiatry 28: $925-932$.

23. Thase ME, Larsen KG, Kennedy SH (2011) Assessing the "true" effect of active antidepressant therapy $v$ placebo in major depressive disorders: use of a mixture model. Br J Psychiatry 199: 501-507.

24. Sonawalla SB, Rosenbaum JF (2002) Placebo response in depression. Dialogues Clin Neurosci 4: 105-113.

25. Arroll B, Elley CR, Fishman T, Goodyear-Smith FA, Kenealy T, et al. (2009) Antidepressants versus placebo for depression in primary care. Cochrane Database Syst Rev CD007954.

26. Fournier JC, DeRubeis RJ, Hollon SD, Dimidjian S, Amsterdam JD, et al (2010) Antidepressant drug effects and depression severity: a patient-level meta-analysis. JAMA 303: 47-53.

27. Reynolds E (2006) Vitamin B12, folic acid, and the nervous system. Lance Neurol 5: 949-960.

28. Bottiglieri T (2013) Folate, vitamin B12, and S-Adenosylmethionine. Psychiatr Clin North Am 36: 1-13.

29. Bottiglieri T, Hyland K, Reynolds EH (1994) The clinical potential of ademetionine (S-adenosylmethionine) in neurological disorders. Drugs 48 : 137-152.

30. Reynolds EH, Carney MW, Toone BK (1984) Methylation and mood. Lancet 2: 196-198.

31. Durga J, van Boxtel MP, Schouten EG, Kok FJ, Jolles J, et al. (2007) Effect of 3 -year folic acid supplementation on cognitive function in older adults in the FACIT trial: a randomised double-blind controlled trial. Lancet 369: 208-216.

32. Smith AD, Smith SM, de Jager CA, Whitbread P, Johnston C, et al. (2010) Homocysteine-lowering by $\mathrm{B}$ vitamins slows the rate of accelerated brain atrophy in mild cognitive impairment: a randomised controlled trial. PLoS One 5: e12244.

\section{Acknowledgements}

Funding: Bioresearch, Milan supplied 5-MTHF and financial support for Teodoro Bottiglieri for this study.

Ethical approval: The study was approved by the ethical committees of King's College and Northwick Park Hospitals.

Guarantor: Dr. E.H. Reynolds 